AMERICAN JOURNAL BIOTECHNOLOGY AND MOLECULAR SCIENCES

ISSN Print: 2159-3698, ISSN Online: 2159-3701, doi:10.5251/ajbms.2011.1.2.57.68

(C) 2011, ScienceHu $\beta$, http://www.scihub.org/AJBMS

\title{
Biodegradation of fungicide Thiram (TMTD) in soil under laboratory conditions
}

\author{
A. M. Sherif ${ }^{1}$, A. A. Elhussein ${ }^{2}$ and A. G. Osman ${ }^{1}$ \\ ${ }^{1}$ Biofertilization Department, Environment and Natural Resource Research Institute, National \\ Center for Research \\ E-mail: ashrafmsg@hotmail.com \\ E-mail: agosman@hotmail.com \\ ${ }^{2}$ Botany Department, Faculty of Science, University of Khartoum, Khartoum, Sudan \\ E-mail: adilelhussein@hotmail.com
}

\begin{abstract}
In vitro studies were carried out, using four selective media, to determine the effect of the main groups of soil microorganisms on the degradation of fungicide Thiram in soil. Soil from El Geraif (East Khartoum) that had no history of pesticide exposition was chosen to conduct this experiment. In general, Thiram have a fluctuating effect on the growth of organic nitrogen using bacteria up to 13 weeks of incubation after which a steady increase in the numbers of these microorganisms was observed. This was found to coincide with the lack of the fungicide residue in soil. Soil fungi were the most affected by the addition of the fungicide Thiram compared to other major groups of soil microorganisms. Although to a lesser extent Thiram have negatively affected the growth of inorganic nitrogen using bacteria and actinomycetes. On the other hand the fungicide has stimulated the growth of soil microorganisms capable of growing on poor media (Nitrate Agar). Microbial degradation of the fungicide Thiram in soil was assessed under laboratory conditions. Fungicide residues in soil were determined in synchronization with microbial counts. Under laboratory conditions, soil microorganisms degraded Thiram in a period ranging from two to eight weeks depending on its concentration. Maximum degradation percentage $(97.36 \%)$ was recorded after eight weeks of incubation. The half - life of fungicide Thiram in soil determined in this study is 10 days at $\mathrm{pH} 7.8$ at room temperature.
\end{abstract}

Keywords: Thiram, Biodegradation, Soil microorganisms.

\section{INTRODUCTION}

Thiram belongs to the ethylene bisdithiocarbamate (EBDC) chemical class. The EBDCs are fungicides used to prevent crop damage in the field and to protect harvested crops from deterioration in storage or transport (National Institute of Safety and Health (NIOSH), 1986). Thiram is used as seeds, fruit, vegetable, ornamental and turf crops protectant from a variety of fungal diseases. It is also used as an animal repellent to protect fruit trees and ornamentals from damage by rabbits, rodents and deer. In Sudan Thiram (TMTD 25 D) was introduced in the year 1976 for the control of loose and covered smuts, dampingoff diseases and as a seed protectant during storage periods. Thiram is moderately toxic by ingestion, but it is highly toxic if inhaled. Acute exposure in humans may cause headaches, dizziness, fatigue, nausea, diarrhea and other gastrointestinal complaints. Also drowsiness, confusion, incoordination, slurred speech and weakness. Repeated or prolonged exposure to Thiram can also cause allergic reactions such as dermatitis, watery eyes, sensitivity to light and conjunctivitis ((Hayes and Laws, 1990; U.S. National Library of Medicine, 1995). All of the EBDC pesticides can be degraded or metabolized into ethylenethiourea (ETU), which has been classified as a probable human carcinogen by EPA (U.S. EPA, 1992 (March 2)).

Microbial degradation is an important step in the disappearance and, in most cases detoxification of pesticides. Many soil applied pesticides are degraded more rapidly following repeated application at the same site (Kauffman, 1987; Racke and Coats, 1990). It is well known that fungicides which are not easily degradable have the greatest effects on microbes. These types of pesticides, adversely affect fungi and bacteria which may lead to the break down of food chains and consequently the disturbance of the 
natural balance (Shirkot and Gupta, 1985; Shirkot et al, 1990). The indiscriminate use of pesticides may aggravate a disease situation rather than control it. This is a common occurrence with fungicides, which are usually applied to soil at high rates. Odeyemi and Alexander (1977) reported that treatment of legume seeds with Thiram, Spergon and Phygon before rhizobial inoculation decreased the weight of plants and nitrogen fixation considerably. Some factors, like temperature and humidity influence pesticides effect on microorganisms. The inhibitory effect of pesticides on the growth of bacteria and actinomycetes was reported to be at high temperatures (Klinsari, 1983). Thiram degrades by microbial action or by hydrolysis more rapidly in acidic soils and in soils high in organic matter. In a humus sandy soil, at $\mathrm{pH} 3.5$, Thiram decomposed after 4 to 5 weeks, while at $\mathrm{pH} 7.0$, Thiram decomposed after 14 to 15 weeks. Thiram persisted for over two months in sandy soils, but disappeared within one week from a compost soil. The major metabolites of Thiram in the soil are copper dimethyl-dithiocarbamate, dithiocarbamate, dimethylamine and carbon disulfide. Minor degradative products included nitrite ions (nitrate reduction) and dimethylnitrosamine (Ayanaba et al., 1973). Richardson (1954) reported more than 95\% conversion of Thiram to metabolites by soil microorganisms after 55 days of incubation. The harmful effects of pesticides are generally studied for many communities and individuals in the ecosystem, but very few studies were devoted for investigating the effects of soil microorganisms on the degradation of pesticides in soil. Moreover, results of these few studies (Zincheno et al., 1974 and Kruglov, 1991) revealed fluctuating results.

\section{MATERIALS AND METHODS}

Effect of Fungicide Thiram on Soil Microorganisms : Soil samples were collected from El Geraif, East of Khartoum where there is no history of pesticides application. Auger samples were randomly taken at $10 \mathrm{~cm}$ depth from different parts in the selected site. Large clods in each sample were crushed to a uniform reasonable size, mixed thoroughly to make a composite sample and air dried at room temperature. Some characteristics of the soil were determined according to the methods described in Ryan et al. (1996). The soil used in this study was heavy clay containing $52 \%$ clay, $47 \%$ silt, $1 \%$ sand and $0.1834 \%$ total $\mathrm{N}, 0.00034 \% \mathrm{P}_{2} \mathrm{O}_{5}$, $0.027 \% \mathrm{~K}_{2} \mathrm{O}, 0.36018 \%$ O.C, $0.62095 \%$ O.M at $\mathrm{pH}$ 7.8.
The soil was then divided into $600 \mathrm{~g}$ lots and each lot was transferred into $1000 \mathrm{ml}$ beaker, wetted with water to $60 \%$ field capacity and a specific Thiram concentration was then added to each beaker. Thiram concentrations ( $\mathrm{mg} / \mathrm{g}$ soil) used were: 0 , $0.0228,0.0457,0.0913,0.1827$ and 0.4567 .

Beakers were then incubated in the dark for 18 weeks. A control set to which no pesticide has been added was prepared, following the same procedure, for comparison. At zero time and then at 2, 4, 8, 10, 13 and 18 weeks, soil samples were taken for viable counts on four different media which were prepared by dissolving the ingredients of each $(\mathrm{g})$ in one litre of distilled water as follows (Tepper et al., 1993):

Meat Peptone Agar (MPA): Meat extract, 5.0; Peptone, 7.5; Sodium chloride, 5.0 and Agar, 20.0.

Czapeks Dox Agar (CZA): Sucrose, 20.0; Sodium, 2.0; Dipotassium hydrogen phosphate, 1.0; Magnesium sulphate, hepta - hydrated, 0.5; Potassium chloride, 0.5; Calcium carbonate, 3.0 and Agar, 20.0.

Starch Ammonium Agar (SAA): Starch, 10.0; Ammonium sulphate, 2.0; Dipotassium hydrogen phosphate, 1.0; Magnesium sulphate, hepta hydrated, 1.0; Sodium chloride, 1.0; Calcium carbonate, 3.0 and Agar, 20.0.

Nitrate Agar (NA): Sodium nitrite, 0.1; Sodium carbonate, 0.1; Sodium chloride, 0.05; Dipotassium hydrogen phosphate, 0.05 ; Magnesium sulphate hepta - hydrated, 0.05; Ferrous sulphate - hydrated, 0.04 and Agar, 15.0.

Viable Counts in Thiram Wetted Soil: Ten grams of Thiram - wetted soil were dissolved in $90 \mathrm{ml}$ of sterilized distilled water in a $250 \mathrm{ml}$ conical flask. The contents were shaken well to give the first dilution $\left(10^{-1}\right)$. One $\mathrm{ml}$ of this dilution was carefully transferred by a micropipette to $9 \mathrm{ml}$ of sterilized distilled water to give the second dilution $\left(10^{-2}\right)$. The third to the ninth dilutions $\left(10^{-3}-10^{-9}\right)$ were prepared in a similar way. One $\mathrm{ml}$ inoculum from each of dilution $10^{-8}$ and $10^{-9}$ were transferred to the agar surface of MPA, SAA and NA plates. Similarly one $\mathrm{ml}$ inoculum from each of dilutions $10^{-3}$ and $10^{-4}$ were transferred and spreaded over CZA plates. In each case, the inoculum was spreaded on top of the agar surface using sterilized glass spreaders and the plates were incubated at $28^{\circ} \mathrm{C}$. The periods of incubation were two days for MPA, Three days for CZA, 10 days for SAA and 7 days for NA medium. At the end of the incubation period, the number of bacterial/ fungal 
colonies were counted and viable counts were calculated as follows:

On MPA, CZA and SAA, viable counts were determined according to the formula:

$\mathrm{N}=\quad \frac{\text { a.d }}{\text { Wt.V }}$ as suggested by Tepper et al. (1993).

Where:

$\mathrm{N}=$ Number of colonies /g dry soil.

$\mathrm{a}=$ Average number of colonies .

$\mathrm{d}=$ Dilution factor .

$\mathrm{V}=$ Volume of inoculum spreaded in Petri dish.

$\mathrm{Wt}=$ Dry weight of soil sample $(\mathrm{g})$.

Viable counts on NA plates were determined under stereo microscope using the formula:

$\mathrm{N}=\frac{\sum \text { a.100.h }}{\text { n.CB.v }}$ according to Tepper et al. (1993).

Where:

$\mathrm{N}=$ Number of colonies / $\mathrm{g}$ dry soil.

$\Sigma a=$ Average number of colonies.

$\mathrm{h}=$ The dilution factor.

$\mathrm{n}=$ Number of looks.

$\mathrm{CB}=$ Dry weight of soil sample $(\mathrm{g})$.

$\mathrm{V}=$ Volume of inoculum spreaded in Petri dish.

251.8328 = Constant for objective (45X).

Determination of Thiram Residues in Soil: Ten grams of Thiram - wetted soil were transferred into a $250 \mathrm{ml}$ conical flask and $50 \mathrm{ml}$ Acetonitrile (HPLC grade) were added to it. The contents were vigorously shaken for 15 minutes and $20 \mu$ l were transferred and injected into the chromatograph (Waters, USA) with UV detector. Other conditions were as follows: column: Lichromosorb RPC ${ }_{18}(25 \mathrm{~cm}$ x 3.9-mm-ID stainless steel), column temperature $25^{\circ} \mathrm{C}$, mobile phase: $60 \%$ acetonitrile: $40 \%$ water, injection volume: $20 \mu \mathrm{l}$, Mobile phase flow rate 1 $\mathrm{ml} / \mathrm{min}$, detection: UV at $254 \mathrm{~nm}(1-\mathrm{cm}$ cell), retention time: $3.8 \mathrm{~min}$, Calibration: standard solutions of Thiram in acetonitrile. Residues of Thiram were determined at zero time and then at 2, 4, 8, 10, 13 and 18 weeks.

Half - life of Thiram in Soil: Residues of Thiram in soil after 18 weeks of incubation were used to calculate the half - life of the fungicide using the following equation as suggested by Müller et al. (2006):

$\mathrm{T}_{1 / 2}=\frac{0.693}{\mathrm{~K}}$

Where:

$\mathrm{T}_{1 / 2}=$ The half - life.

$\mathrm{K}=$ The degradation rate constant.
The degradation rate constant can be calculated with the following equation:

$K=\frac{2.303}{t} \log \left(C_{0} / C_{t}\right)$

Where:

$\mathrm{C}_{0}=$ The initial concentration (ppm).

$\mathrm{C}_{\mathrm{t}}=$ The concentration at time $\mathrm{t}(\mathrm{ppm})$.

\section{RESULTS AND DISCUSSIONS}

Effect of Thiram on Organic Nitrogen using Bacteria: Inhibition or increment percentages in the numbers of organic nitrogen using bacteria by different Thiram concentrations in soil incubated at $25^{\circ} \mathrm{C}$ is shown in Fig 1 . It is obvious that, different concentrations of Thiram have stimulated the growth of organic nitrogen users after 18 weeks of incubation at all fungicide concentrations used. The stimulatory effect was also observed after two weeks of incubation at the concentrations $0.0228,0.0913$ and $0.1827 \mathrm{mg} / \mathrm{g}$ of fungicide. Compared to the control, the maximum increment percentage (3577.8\%) in the numbers of organic nitrogen users was observed after two weeks of incubation in soil treated with fungicide at $0.0913 \mathrm{mg} / \mathrm{g}$ (Fig. 1c). The increment percentage in the numbers of organic nitrogen users reached a maximum value of $16734 \times 10^{8}$ compared to the control $\left(455 \times 10^{8}\right)$ cells $/ g$ of soil.

All fungicide treated soils showed inhibitory effect at different incubation periods in the range of $7 \%$ up to $100 \%$. After four weeks of incubation all fungicide concentrations showed a strong inhibitory effect on organic nitrogen users. The maximum inhibition percentage $(100 \%)$ was observed in soil treated with fungicide at $0.0457 \mathrm{mg} / \mathrm{g}$ and $0.0913 \mathrm{mg}$ fungicide $/ \mathrm{g}$ soil after eight and 13 weeks of incubation respectively (Fig. $1 \mathrm{~b}$ and $1 \mathrm{c}$ ). In general, Thiram have a fluctuating effect on the growth of organic nitrogen using bacteria up to 13 weeks of incubation after which a steady increase in the numbers of these organisms was observed. This was found to coincide with the lack of the fungicide residue in soil.

Osman et al. (1999) found that Amistar fungicide did not render a conspicuous effect on organic nitrogen users, while Suleman (1983) reported that, Simazine and Atrazine herbicides inhibited the growth of organic nitrogen users. Ekundayo (2002) found that Thiram depressed soil bacterial population by two orders of magnitude, while Mohamed (2009) reported a fluctuating effect of oxyfluorfen herbicide on the number of organic nitrogen using bacteria with maximum inhibition and increment percentages of 
65.2 and $93.3 \%$, respectively when compared to controls.

Effect of Thiram on Soil Fungi: Inhibition or increment percentages of fungal population by different Thiram concentrations in soil incubated at $25^{\circ} \mathrm{C}$ are shown in Fig 2.

Thiram concentrations of 0.0913 and $0.4567 \mathrm{mg}$ fungicide/g soil have inhibited the growth of fungi during the incubation period (18 weeks). In soil treated with the fungicide at $0.0228 \mathrm{mg}$ fungicide $/ \mathrm{g}$ soil the number of fungi increased by $90.71 \%$ after 10 weeks of incubation (fig 2a). However, in soils treated with 0.0457 and $0.1827 \mathrm{mg}$ fungicide/g soil the total number of fungi increased by $441.67 \%$ and $93.75 \%$ respectively after eight weeks of incubation (fig $2 \mathrm{~b}$ and $2 \mathrm{~d}$ ). The highest percentage of inhibition $(98.51 \%)$ was observed at $0.0913 \mathrm{mg}$ fungicide/g soil after 18 weeks of incubation (fig 2c). Soil fungi were the most affected by the addition of the fungicide Thiram compared with other major groups of soil microbes.

Houseworth and Tweedy (1973), found that Captan and Thiram caused an initial decrease in the fungal populations but after 108 days of incubation the populations returned to levels comparable to those found in untreated soils. They also reported that Thiram did not persist long enough to keep the fungal populations suppressed longer than about 16 days. Abdel Mallek et al. (1992, 1997) found that Benlate and Captan inhibited the growth and spore formation of five species of fungi. Osman et al. (1999) found that Amistar fungicide inhibited the growth of fungi at different concentrations for up to 150 days. Ekundayo (2002) found that Thiram depressed the fungal population by one order of magnitude. Roberti et al. (2006) reported that mycelial growth and conidial germination of different Trichoderma species had a broad range of sensitivity to Thiram. Mohamed (2009) reported a fluctuating effect of herbicide Oxyfluorfen on soil fungal populations.

Effect of Thiram on Inorganic Nitrogen using Bacteria and Actinomycetes: Table 1 shows the effect of Thiram on the growth of inorganic nitrogen using bacteria and actinomycetes. It is clear that after 4 and 10 weeks of incubation, Thiram decreased the total number of inorganic nitrogen users at all concentrations tested. The maximum inhibition percentage $(96.80 \%)$ was observed at the fungicide concentration of $0.4567 \mathrm{mg} / \mathrm{g}$ after two weeks of incubation. After 18 weeks, the greatest stimulatory effect on the growth of inorganic nitrogen users was observed at $0.0228 \mathrm{mg}$ fungicide/g soil as reflected by the number of inorganic nitrogen users of $2413 \times 10^{6}$ while for the control was $500 \times 10^{6} \mathrm{cells} / \mathrm{g}$ of soil.

After 2, 8, 10 and 13 weeks of incubation Thiram showed a strong inhibitory effect on the total number of actinomycetes at all tested concentrations of the fungicide. The highest inhibition percentage (98.53\%) was observed at $0.0913 \mathrm{mg}$ fungicide/g soil after 10 weeks of incubation. Increment percentages of actinomycetes populations of $250,33.33$ and $16.67 \%$ were observed at the fungicide concentrations of $0.0228,0.0457$ and $0.0913 \mathrm{mg}$ fungicide/g soil respectively after four weeks of incubation. We can generally conclude that Thiram have negatively affected the growth of inorganic nitrogen using bacteria and actinomycetes.

It was reported that the inhibitory effect of pesticides on the growth of bacteria and actinomycetes was high at high temperatures (Klinsari, 1983). Ekundayo (2002) reported that Thiram was most toxic to protozoa, bacteria and fungi but did not affect actinomycetes. Osman (2006) reported the stimulatory effect of the fungicide Azoxystrobin on the growth of actinomycetes, whereas no significant effect was observed on inorganic nitrogen using bacteria. Elsaid and Abdelbagi (2010) found that bacteria and actinomycetes which lives in poor media was higher in soils of cotton field followed by soil of pesticide stores and less in soils of residential areas. Mohamed (2009) reported a fluctuating effect of goal on the numbers of actinomycetes in soils incubated at $28^{\circ} \mathrm{C}$.

Effect of Thiram on Soil Microorganisms Capable of Growing on Poor Medium: As shown in Table 2, application of Thiram increased the total number of all microorganisms capable of growing on poor media (Nitrate agar) at all concentrations tested after 2, 4, 8, 10 and 18 weeks of incubation. The maximum increment percentage $(464.07 \%)$ was observed at $0.1827 \mathrm{mg} / \mathrm{g}$ soil after four weeks of incubation. A strong stimulatory effect on the growth of the same microorganisms was also observed at Thiram concentrations of $0.0913 \mathrm{mg} / \mathrm{g}$ soil and $0.0228 \mathrm{mg} / \mathrm{g}$ after 8 and 18 weeks, respectively. The increments were $309.31 \%$ and $152.19 \%$ in the case of 0.0228 and $0.0913 \mathrm{mg} / \mathrm{g}$ soil Thiram concentrations, respectively. Inhibitory effects on the growth of microorganisms were observed after 13 weeks of incubation at all Thiram concentrations with maximum inhibition of $91.7 \%$ at $0.4567 \mathrm{mg} / \mathrm{g}$ soil. 
Results obtained demonstrated that Mycobacterium species were $100 \%$ dominant at various Thiram concentrations after 4, 8 and 18 weeks of incubation which indicate that Thiram had a strong stimulatory effect on the growth of Mycobacterium species. Maximum increment $(400 \%)$ was recorded after four weeks at $0.4567 \mathrm{mg}$ Thiram $/ \mathrm{g}$ soil fungicide concentration. A Strong inhibitory effect was observed after 13 weeks of incubation at all Thiram tested concentrations. Maximum inhibition (93.23\%) was observed after 13 weeks at Thiram concentration $0.4567 \mathrm{mg} / \mathrm{g}$ soil.

Increments in the numbers of the genus Micromonospora as a result of Thiram addition were observed after 2, 4 and 10 weeks of incubation. The highest increment percentage $(200 \%)$ of the numbers of Micromonospora was observed at $0.0913 \mathrm{mg} / \mathrm{g}$ soil after 10 weeks of incubation. The number was $120.4 \times 10^{6}$ and that for the control was $60.2 \times 10^{6}$ cells/g of soil. Absence of growth for Micromonospora at all tested concentrations and the controls were observed after 8 and 18 weeks of incubation. Total inhibition $(100 \%)$ of the numbers of Micromonospora at all tested concentrations was observed after 13 weeks of incubation.

Increments in the numbers of Arthrobacter were observed at different fungicide concentrations and different incubation periods. The maximum increment percentage $(5312 \%)$ was observed after eight weeks of incubation at $0.0913 \mathrm{mg} / \mathrm{g}$ soil. The number of Arthrobacter was $5116.70 \times 10^{6}$ and that for the control was $96.315 \times 10^{6} \mathrm{cell} / \mathrm{g}$ soil. Inhibition in the numbers of the genus Arthrobacter after 2, 4, 8, 10, 13 and 18 weeks of incubation were observed as a result of Thiram application. Maximum inhibition percentage $(100 \%)$ was observed at some Thiram concentrations after $4,8,10$ and 18 weeks of incubation and a total inhibitory effect was observed after four weeks of incubation at all Thiram tested concentrations.

Inhibition in the numbers of the genus Nocardia was observed after two weeks of incubation. Absence of Nocardia at all tested concentrations and in the controls was observed after four and eight weeks of incubation, while a stimulatory effect was observed after 10, 13 and 18 weeks at different Thiram concentrations. A strong stimulatory effect on the growth of Nocardia was observed at Thiram concentrations of 0.0228 and $0.1827 \mathrm{mg} / \mathrm{g}$ soil respectively after 10 weeks of incubation, the number was $722.35 \times 10^{6}$ and that for the control was zero.

A Stimulatory effect on the growth of Bactoderma was observed after 2 and 13 weeks of incubation at Thiram concentrations of 0.0228 and $0.0457 \mathrm{mg} / \mathrm{g}$ soil. Maximum growth increment was recorded at Thiram concentration of $0.0457 \mathrm{mg} / \mathrm{g}$ soil after 13 weeks of incubation. Bactoderma count was $120.4 \times 10^{6}$ cells $/ g$ soil and that for the control was zero. Bactoderma colonies were not observed neither at Thiram concentrations of 0.0913 and $0.4567 \mathrm{mg} / \mathrm{g}$ nor in the control.

Osman et al. (2005) studied the effect of Azoxystrobin fungicide on soil microorganisms capable of growing on poor media at $40^{\circ} \mathrm{C}$ and reported that, the fungicide stimulated the growth of Arthrobacter, Mycobacterium and Nocardia. Ali et al., (2008) found that Mycobacterium and Bactoderma were known to have better adaptability to highly polluted soils. They also found that addition of Endosulfan and lindane insecticides to the growth media (MPA, SAA and NA) resulted in an increase in the counts of all microorganisms. Moreover, the growth of Micromonospora was found to be associated with the application of the insecticide endosulfan $\beta$. Elsaid et al. (2009) found that application of endosulfan insecticide and urea + phosphate fertilizers increased the number of Mycobacterium, Micromonospora, Arthrobacter, Nocardia and Bactoderma in soils after 45 days of incubation. He also related the increments in the level of this group in store soil to the increments in the counts of Mycobacterium and Bactoderma. Mohamed (2009) found that Mycobacterium species were absolutely dominant in comparison with other soil microorganisms capable of growing on poor media (Nitrate Agar).

Biodegradation of Thiram in Soil : Results obtained for biodegradation of Thiram in soil demonstrated that $41 \%$ of the fungicide was degraded after two weeks of incubation while $90 \%$ was degraded after four weeks of incubation. Maximum degradation percentage $(97.36 \%)$ was recorded after eight weeks of incubation (Fig 3). Results obtained also indicate that degradation rates were inversely proportional to concentration. At Thiram concentration of $0.0228 \mathrm{mg} / \mathrm{g}$ soil, degradation 


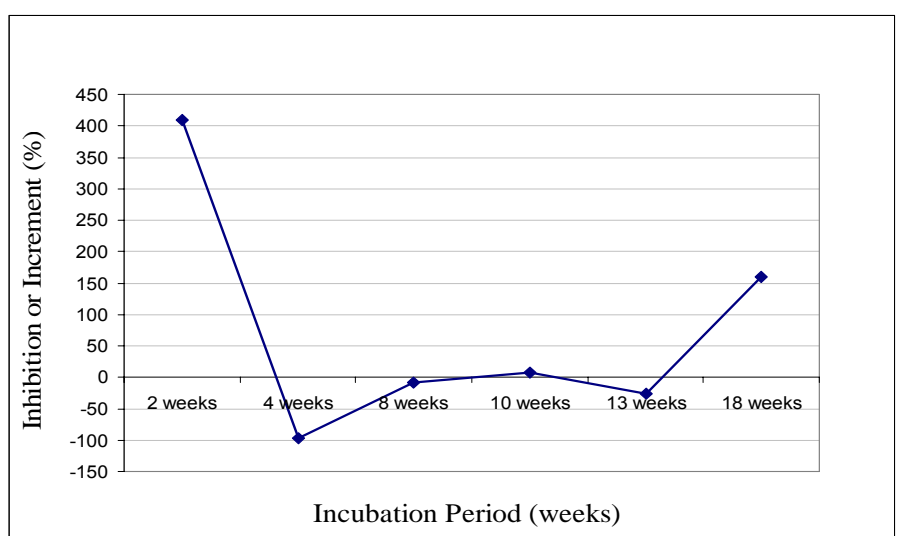

Thiram concentration $0.0228 \mathrm{mg} / \mathrm{g}$ soil

(a)

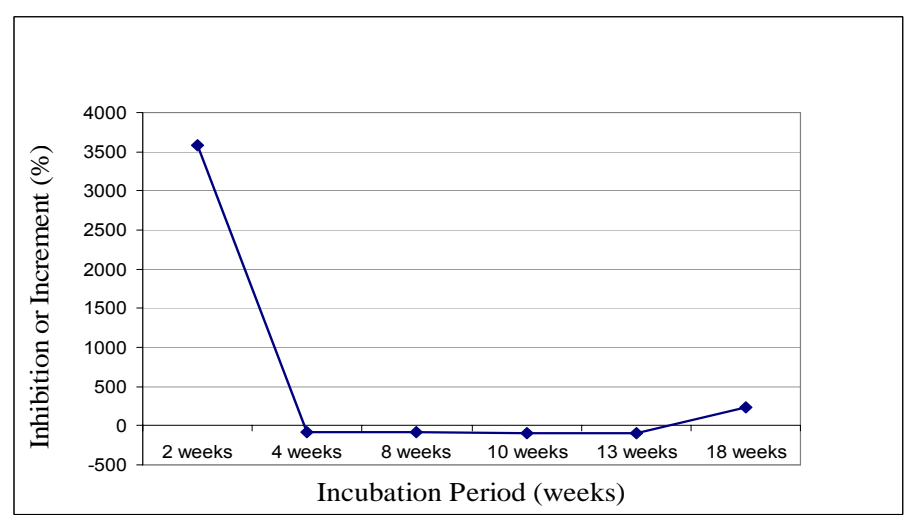

Thiram concentration $0.0913 \mathrm{mg} / \mathrm{g}$

(c)

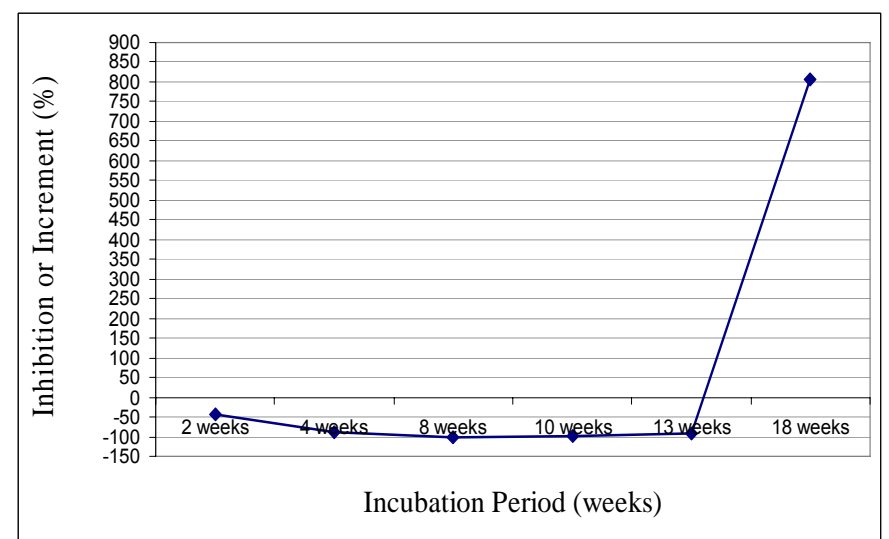

Thiram concentration $0.0457 \mathrm{mg} / \mathrm{g}$

(b)

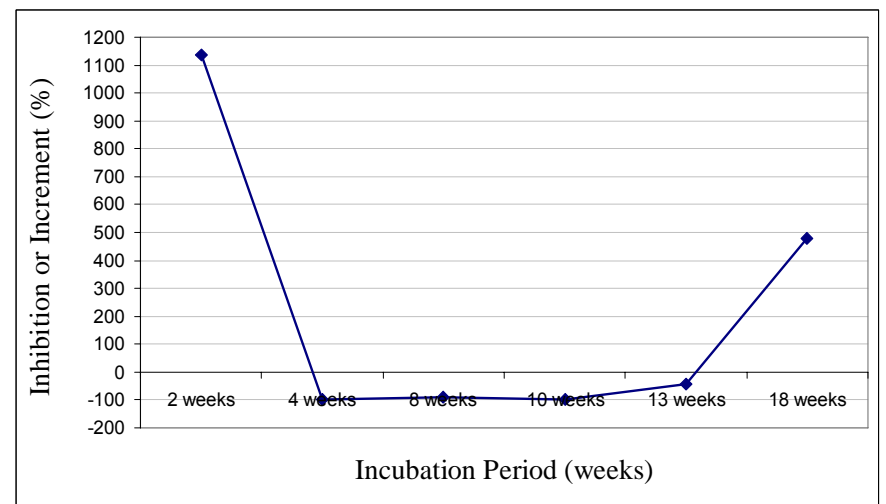

Thiram concentration $0.1827 \mathrm{mg} / \mathrm{g}$

(d)

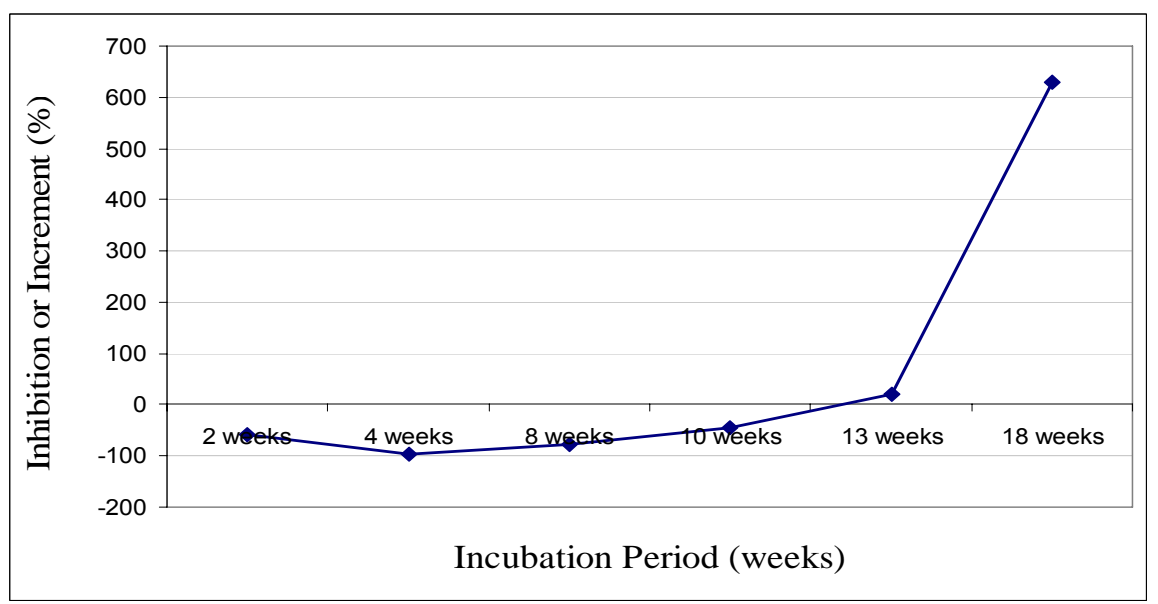

Thiram concentration $0.4567 \mathrm{mg} / \mathrm{g}$

(e)

Fig 1. Inhibition or Increment percentages of Organic Nitrogen using Bacteria in El Geraif Soil Incubated at $25^{\circ} \mathrm{C}$. 


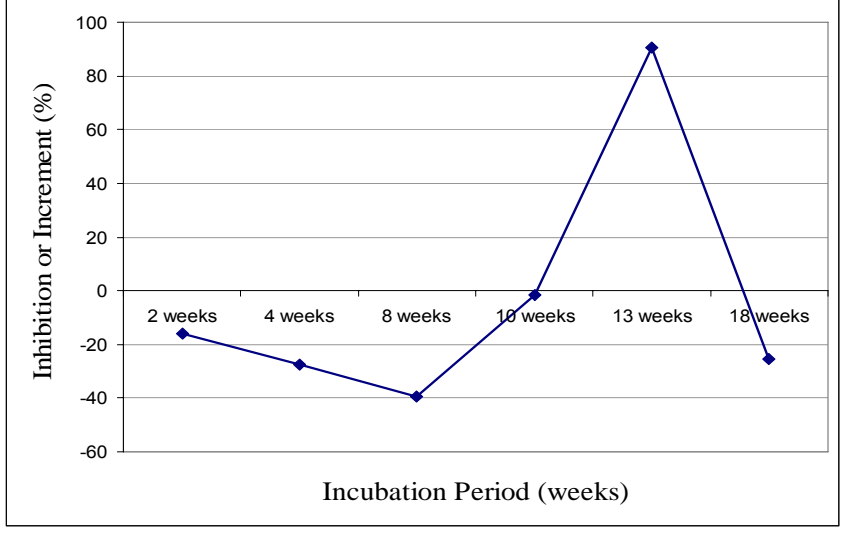

Thiram concentration $0.0228 \mathrm{mg} / \mathrm{g}$

(a)

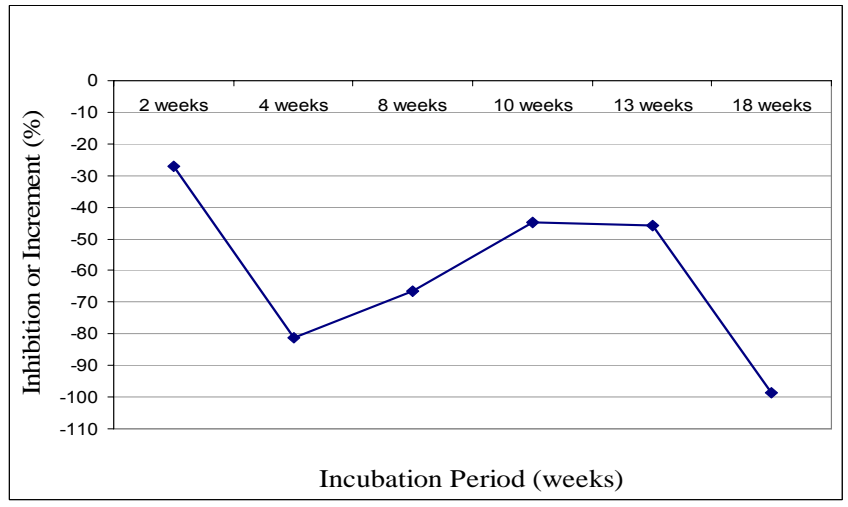

Thiram concentration $0.0913 \mathrm{mg} / \mathrm{g}$

(c)

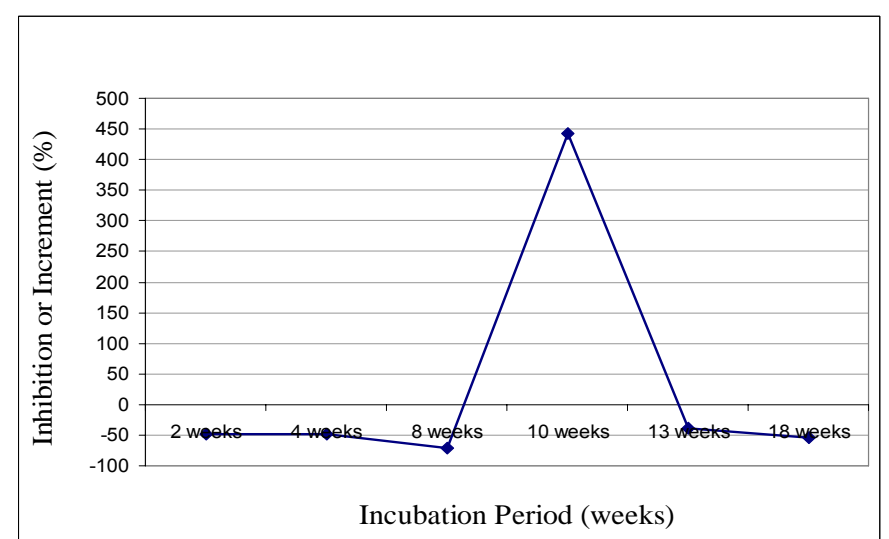

Thiram concentration $0.0457 \mathrm{mg} / \mathrm{g}$

(b)

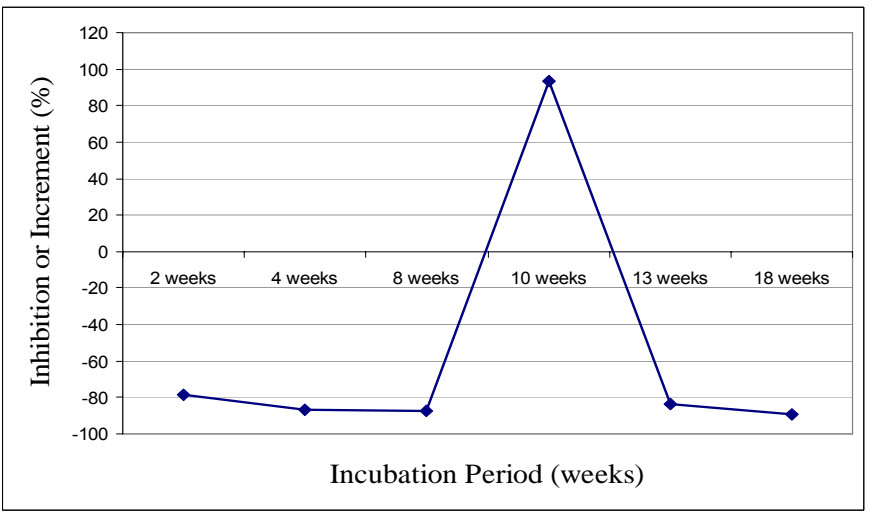

Thiram concentration $0.1827 \mathrm{mg} / \mathrm{g}$

(d)

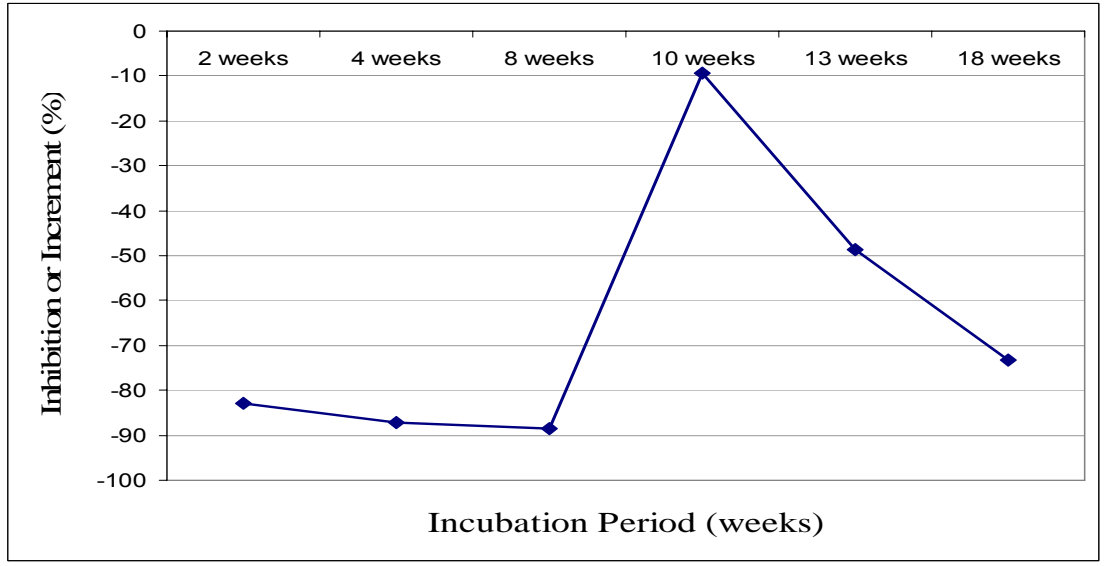

Thiram concentration $0.4567 \mathrm{mg} / \mathrm{g}$

(e)

Fig 2. Inhibition or Increment percentages of Soil Fungi in El Geraif Soil Incubated at $25^{\circ} \mathrm{C}$. 
Table 1. Effect of Different Concentrations of Thiram on Soil Microorganisms Capable of Growing on Starch Ammonium Agar.

\begin{tabular}{|c|c|c|c|c|c|c|}
\hline \multirow{2}{*}{ Counts $\left(10^{6}\right)$} & \multicolumn{6}{|c|}{ TMTD doses (mg/g soil) } \\
\hline & 0.0 & 0.0228 & 0.0457 & 0.0913 & 0.1827 & 0.4567 \\
\hline \multicolumn{7}{|c|}{ At zero time } \\
\hline Total $\left(\mathrm{X10}^{6}\right)$ & 9416 & 0 & 3231.5 & 8900 & 4983.5 & 4280 \\
\hline \% Inhibition - Increment & 0 & 0 & -65.68 & -5.48 & -47.07 & -54.55 \\
\hline Actinomycetes $\left(\mathrm{X}^{6}{ }^{6}\right)$ & 0 & 0 & 10 & 41.5 & 0 & 90.0 \\
\hline \% Inhibition - Increment & 0 & 0 & 0 & 0 & 0 & 0 \\
\hline \% Actinomycetes to total & 0 & 0 & 0.31 & 0.47 & 0 & 2.1 \\
\hline \multicolumn{7}{|c|}{ After 2 weeks } \\
\hline Total $\left(\mathrm{X10}^{6}\right)$ & 81900 & 183800 & 35750 & 310725 & 153650 & 2625 \\
\hline$\%$ Inhibition - Increment & 0 & +124.42 & -56.35 & +279.40 & +87.61 & -96.80 \\
\hline Actinomycetes $\left(\mathrm{X}^{6}{ }^{6}\right)$ & 1500 & 375 & 625 & 875 & 0 & 75 \\
\hline \% Inhibition - Increment & 0 & -75 & -58.33 & -41.67 & 0 & -95 \\
\hline \% Actinomycetes to total & 1.83 & 0.20 & 1.75 & 0.28 & 0 & 2.86 \\
\hline \multicolumn{7}{|c|}{ After 4 weeks } \\
\hline Total $\left(\mathrm{X}^{6} 0^{6}\right)$ & 110550 & 32200 & 204725 & 5575 & 14425 & 19400 \\
\hline \% Inhibition - Increment & 0 & -70.87 & +85.19 & -94.96 & -86.95 & -82.45 \\
\hline Actinomycetes $\left(\mathrm{X10}^{6}\right)$ & 450 & 1575 & 600 & 525 & 250 & 0 \\
\hline \% Inhibition - Increment & 0 & +250 & +33.33 & +16.67 & -44.44 & 0 \\
\hline$\%$ Actinomycetes to total & 0.41 & 4.89 & 0.29 & 9.42 & 1.73 & 0 \\
\hline \multicolumn{7}{|c|}{ After 8 weeks } \\
\hline Total & 1391125 & 1166125 & 986675 & 57900 & 206675 & 1118175 \\
\hline \% Inhibition - Increment & 0 & -16.17 & -29.07 & -95.83 & -85.14 & -19.62 \\
\hline Actinomycetes $\left(\mathrm{X10}^{6}\right)$ & 600 & 250 & 500 & 525 & 75 & 0 \\
\hline \% Inhibition - Increment & 0 & -58.33 & -16.67 & -12.5 & -87.5 & 0 \\
\hline \% Actinomycetes to total & 0.04 & 0.02 & 0.05 & 0.91 & 0.04 & 0 \\
\hline \multicolumn{7}{|c|}{ After 10 weeks } \\
\hline Total & 26400 & 19825 & 5725 & 52775 & 4300 & 25900 \\
\hline \% Inhibition - Increment & 0 & -24.91 & -78.31 & +99.91 & -83.71 & -1.89 \\
\hline Actinomycetes $\left(\mathrm{X10}^{6}\right)$ & 1700 & 1375 & 50 & 25 & 625 & 150 \\
\hline \% Inhibition - Increment & 0 & -19.12 & -97.06 & -98.53 & -63.24 & -91.18 \\
\hline \% Actinomycetes to total & 6.44 & 6.94 & 0.87 & 0.05 & 14.53 & 0.58 \\
\hline \multicolumn{7}{|c|}{ After 13 weeks } \\
\hline Total $\left(\mathrm{X10}^{6}\right)$ & 6425 & 26900 & 11975 & 1325 & 3100 & 2025 \\
\hline \% Inhibition - Increment & 0 & +318.68 & +86.38 & -79.38 & -51.75 & -68.48 \\
\hline Actinomycetes $\left(\mathrm{X}^{6}{ }^{6}\right)$ & 550 & 50 & 200 & 325 & 100 & 350 \\
\hline \% Inhibition - Increment & 0 & -90.91 & -63.64 & -40.91 & -81.82 & -36.36 \\
\hline \% Actinomycetes to total & 8.56 & 0.19 & 1.67 & 24.53 & 3.23 & 17.28 \\
\hline \multicolumn{7}{|c|}{ After 18 weeks } \\
\hline Total $\left(\mathrm{X10}^{6}\right)$ & 500 & 2413 & 735 & 815 & 938 & 1390 \\
\hline \% Inhibition - Increment & 0 & +382.5 & +47 & +63 & +87.5 & +178 \\
\hline Actinomycetes $\left(\mathrm{X10}^{6}\right)$ & 78 & 20 & 103 & 168 & 130 & 63 \\
\hline \% Inhibition - Increment & 0 & -74.19 & +32.26 & +116.13 & -67.74 & -19.35 \\
\hline \% Actinomycetes to total & 15.5 & 0.83 & 13.95 & 20.55 & 13.87 & 4.50 \\
\hline
\end{tabular}

(\%): Percentage of Inhibition (-) and Increment (+) 
Table 2. Effect of Different Concentrations of Thiram (TMTD) on Soil Microorganisms Capable of Growing on Poor Medium (Nitrate Agar).

\begin{tabular}{|c|c|c|c|c|c|c|c|c|c|c|c|c|}
\hline \multirow{2}{*}{$\begin{array}{c}\text { TMTD } \\
\text { Doses } \\
\text { mg/g } \\
\text { soil }\end{array}$} & \multicolumn{2}{|c|}{ All microorganisms } & \multicolumn{2}{|c|}{ Mycobacterium } & \multicolumn{2}{|c|}{ Micromonospora } & \multicolumn{2}{|c|}{ Arthrobacter } & \multicolumn{2}{|c|}{ Nocardia } & \multicolumn{2}{|c|}{ Bactoderma } \\
\hline & $\begin{array}{c}\text { N. Cells/g } \\
\text { dry soil } \\
\left(\mathrm{X} 10^{6}\right)\end{array}$ & $\%$ & $\begin{array}{c}\text { N. Cells/g } \\
\text { dry soil } \\
\left(\mathrm{X} 10^{6}\right)\end{array}$ & $\%$ & $\begin{array}{c}\text { N. Cells/g } \\
\text { dry soil } \\
\left(\mathrm{X} 10^{6}\right)\end{array}$ & $\%$ & $\begin{array}{c}\mathrm{N} . \\
\text { Cells/g } \\
\text { dry soil } \\
\left(\mathrm{X} 10^{6}\right)\end{array}$ & $\%$ & $\begin{array}{c}\mathrm{N} . \\
\text { Cells/g } \\
\text { dry soil } \\
\left(\mathrm{X} 10^{6}\right)\end{array}$ & $\%$ & $\begin{array}{c}\mathrm{N} . \\
\text { Cells/g } \\
\text { dry soil } \\
\left(\mathrm{X} 10^{6}\right)\end{array}$ & $\%$ \\
\hline \multicolumn{13}{|c|}{ At zero time } \\
\hline $\mathbf{0 . 0}$ & 1359.232 & 100 & 1178.641 & 86.71 & 8.428 & 0.62 & 148.083 & 10.89 & 24.08 & 1.77 & 0 & 0 \\
\hline 0.0228 & 973.979 & 71.66 & 951.705 & 97.71 & 2.408 & 0.25 & 19.866 & 2.04 & 0 & 0 & 0 & 0 \\
\hline 0.0457 & 1780.607 & 131.0 & 1656.602 & 93.04 & 1.204 & 0.07 & 122.801 & 6.9 & 0 & 0 & 0 & 0 \\
\hline 0.0913 & 533.341 & 39.24 & 470.131 & 88.15 & 20.468 & 3.84 & 41.538 & 7.79 & 1.204 & 0.23 & 0 & 0 \\
\hline 0.1827 & 4339.55 & 319.26 & 4134.278 & 95.27 & 0.602 & 0.01 & 186.61 & 4.3 & 0 & 0 & 18.06 & 0.42 \\
\hline 0.4567 & 2390.391 & 175.86 & 2254.951 & 94.33 & 126.41 & 5.29 & 1.806 & 0.08 & 7.224 & 030 & 0 & 0 \\
\hline \multicolumn{13}{|c|}{ After 2 weeks } \\
\hline 0.0 & 10480.155 & 100 & 9450.79 & 90.18 & 138.46 & 1.32 & 764.485 & 7.29 & 126.42 & 1.21 & 0 & 0 \\
\hline 0.0228 & 3746.995 & 35.75 & 3504.75 & 93.53 & 138.905 & 3.71 & 54.76 & 1.46 & 36.54 & 0.98 & 12.04 & 0.32 \\
\hline 0.0457 & 14480.645 & 138.17 & 12112.91 & 83.65 & 1.225 & 0.01 & 2359.175 & 16.29 & 7.335 & 0.05 & 0 & 0 \\
\hline 0.0913 & 15735.29 & 150.14 & 15614.89 & 99.23 & 30.1 & 0.19 & 78.26 & 0.5 & 12.04 & 0.08 & 0 & 0 \\
\hline 0.1827 & 13020.47 & 124.24 & 12894.05 & 99.03 & 0 & 0 & 120.4 & 0.92 & 6.02 & 0.05 & 0 & 0 \\
\hline 0.4567 & 15476.435 & 147.67 & 15422.26 & 99.65 & 0 & 0 & 54.175 & 0.35 & 0 & 0 & 0 & 0 \\
\hline \multicolumn{13}{|c|}{ After 4 weeks } \\
\hline 0.0 & 6970.755 & 100 & 6609.555 & 94.82 & 0 & 0 & 361.2 & 5.18 & 0 & 0 & 0 & 0 \\
\hline 0.0228 & 20159.745 & 289.20 & 20147.705 & 99.94 & 0 & 0 & 12.04 & 0.06 & 0 & 0 & 0 & 0 \\
\hline 0.0457 & 16403.515 & 235.32 & 16162.715 & 98.53 & 180.6 & 1.1 & 60.2 & 0.37 & 0 & 0 & 0 & 0 \\
\hline 0.0913 & 18239.48 & 261.66 & 18239.48 & 100 & 0 & 0 & 0 & 0 & 0 & 0 & 0 & 0 \\
\hline 0.1827 & 32349.455 & 464.07 & 32144.785 & 99.37 & 0 & 0 & 204.67 & 0.63 & 0 & 0 & 0 & 0 \\
\hline 0.4567 & 26420.125 & 379.01 & 26420.125 & 100 & 0 & 0 & 0 & 0 & 0 & 0 & 0 & 0 \\
\hline \multicolumn{13}{|c|}{ After 8 weeks } \\
\hline 0.0 & 96428.375 & 100 & 96332.06 & 99.9 & 0 & 0 & 96.315 & 0.1 & 0 & 0 & 0 & 0 \\
\hline 0.0228 & 18510.335 & 19.20 & 18510.335 & 100 & 0 & 0 & 0 & 0 & 0 & 0 & 0 & 0 \\
\hline 0.0457 & 28201.925 & 29.25 & 28201.925 & 100 & 0 & 0 & 0 & 0 & 0 & 0 & 0 & 0 \\
\hline 0.0913 & 146758.455 & 152.19 & 141641.755 & 96.51 & 0 & 0 & 5116.70 & 3.49 & 0 & 0 & 0 & 0 \\
\hline 0.1827 & 111369.105 & 115.49 & 111369.105 & 100 & 0 & 0 & 0 & 0 & 0 & 0 & 0 & 0 \\
\hline 0.4567 & 17559.24 & 18.21 & 17559.24 & 100 & 0 & 0 & 0 & 0 & 0 & 0 & 0 & 0 \\
\hline \multicolumn{13}{|c|}{ After 10 weeks } \\
\hline 0.0 & 6934.62 & 100 & 6693.82 & 96.53 & 60.2 & 0.87 & 180.6 & 2.60 & 0 & 0 & 0 & 0 \\
\hline 0.0228 & 4015.14 & 57.90 & 2690.79 & 67.02 & 0 & 0 & 602.0 & 15.0 & 722.35 & 18.0 & 0 & 0 \\
\hline 0.0457 & 2401.825 & 34.64 & 2239.29 & 93.23 & 0 & 0 & 42.135 & 1.75 & 120.4 & 5.01 & 0 & 0 \\
\hline 0.0913 & 6182.205 & 89.15 & 5700.605 & 92.21 & 120.4 & 1.95 & 0 & 0 & 361.2 & 5.84 & 0 & 0 \\
\hline 0.1827 & 7330.27 & 105.71 & 6607.92 & 90.15 & 0 & 0 & 0 & 0 & 722.35 & 9.85 & 0 & 0 \\
\hline 0.4567 & 7723.13 & 111.37 & 7163.33 & 92.75 & 0 & 0 & 559.8 & 7.25 & 0 & 0 & 0 & 0 \\
\hline \multicolumn{13}{|c|}{ After 13 weeks } \\
\hline 0.0 & 5459.82 & 100 & 5249.125 & 96.14 & 120.4 & 2.21 & 90.295 & 1.65 & 0 & 0 & 0 & 0 \\
\hline 0.0228 & 3924.82 & 71.89 & 3671.98 & 93.56 & 0 & 0 & 252.84 & 6.44 & 0 & 0 & 0 & 0 \\
\hline 0.0457 & 2642.615 & 48.40 & 1649.365 & 62.41 & 0 & 0 & 571.85 & 21.64 & 301.0 & 11.39 & 120.4 & 4.56 \\
\hline 0.0913 & 866.885 & 15.88 & 722.395 & 83.33 & 0 & 0 & 84.29 & 9.72 & 60.2 & 6.94 & 0 & 0 \\
\hline 0.1827 & 2877.4 & 52.70 & 2799.14 & 97.28 & 0 & 0 & 72.24 & 2.51 & 6.02 & 0.21 & 0 & 0 \\
\hline 0.4567 & 487.615 & 8.93 & 355.175 & 72.84 & 0 & 0 & 72.24 & 14.81 & 60.2 & 12.35 & 0 & 0 \\
\hline \multicolumn{13}{|c|}{ After 18 weeks } \\
\hline 0.0 & 1938.335 & 100 & 1878.135 & 96.89 & 0 & 0 & 60.2 & 3.11 & 0 & 0 & 0 & 0 \\
\hline 0.0228 & 5995.545 & 309.31 & 5995.545 & 100 & 0 & 0 & 0 & 0 & 0 & 0 & 0 & 0 \\
\hline 0.0457 & 1854.04 & 95.65 & 1854.04 & 100 & 0 & 0 & 0 & 0 & 0 & 0 & 0 & 0 \\
\hline 0.0913 & 1360.455 & 70.19 & 1348.415 & 99.12 & 0 & 0 & 12.04 & 0.88 & 0 & 0 & 0 & 0 \\
\hline 0.1827 & 1613.24 & 83.23 & 1547.02 & 95.9 & 0 & 0 & 66.22 & 4.10 & 0 & 0 & 0 & 0 \\
\hline 0.4567 & 1276.165 & 65.84 & 1179.845 & 92.45 & 0 & 0 & 72.24 & 5.66 & 24.08 & 1.89 & 0 & 0 \\
\hline
\end{tabular}


Am. J. Biotechnol. Mol. Sci., 2011, 1(2): 57-68

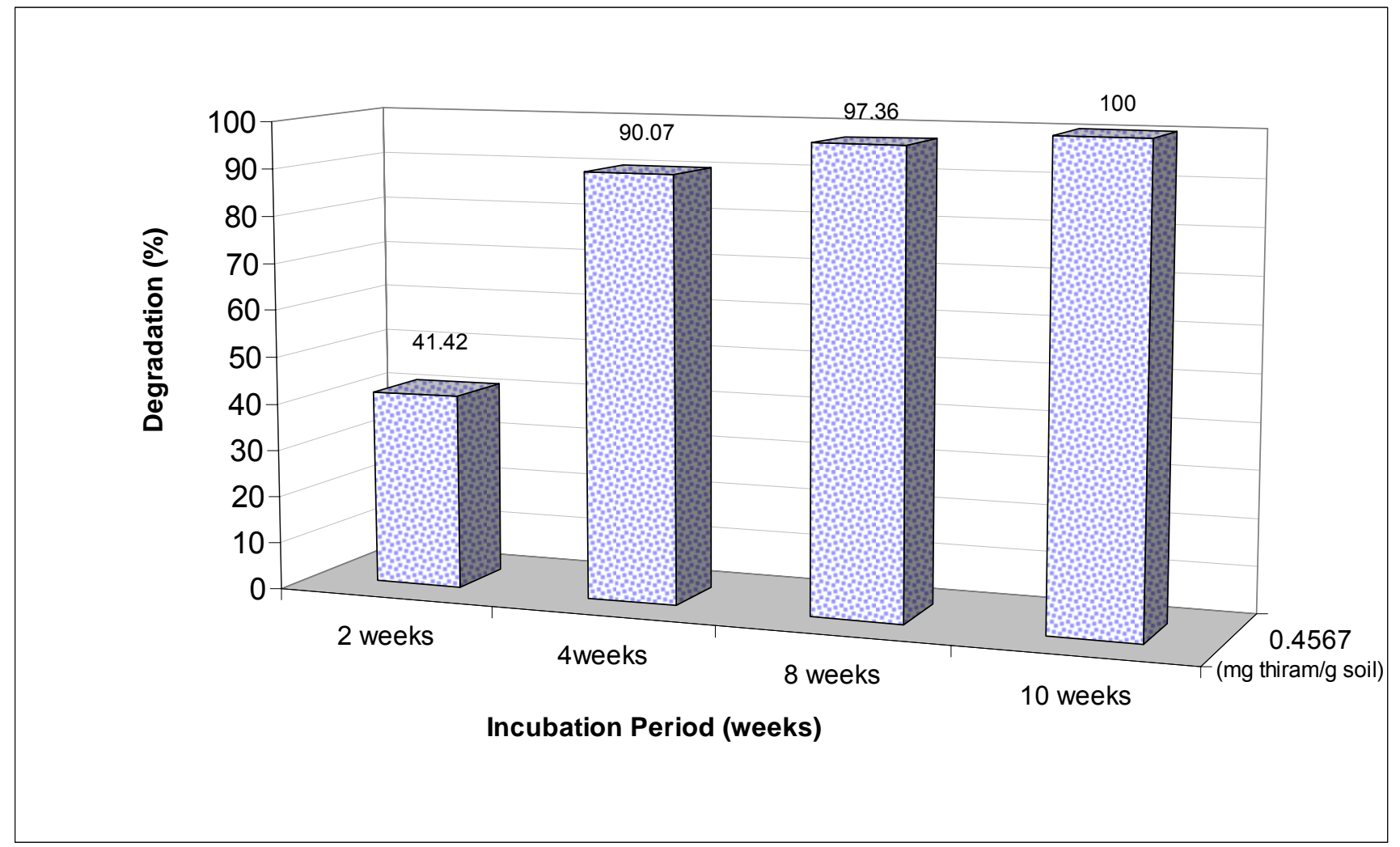

Fig 3. Degradation Rates of Thiram in El Geraif Soil Incubated at $25^{\circ} \mathrm{C}$. 
rates after four and eight weeks of incubation were approximately 16.2 and $100 \%$, respectively.

Shirkot and Gupta (1985) reported that the degradation yields of 85 and $50 \%$ for Thiram concentrations of 100 and 2500 ppm respectively after 24 days incubation. They also concluded that degradation yields of Thiram in soil inversely proportional to concentration.

Richardson (1954) reported that more than $95 \%$ of the TMTD was completely converted to metabolites by soil microorganisms after 55 days of incubation. Kawasaki (1980) reported 30\% Thiram degradation when $100 \mathrm{ppm}$ of Thiram was inoculated with activated sludge $(30 \mathrm{ppm})$ at $25^{\circ} \mathrm{C}$ and $\mathrm{pH} 7.0$ for two weeks. Osman (2006) reported that fungicide azoxystrobin was degraded slowly and existed in the soil up to five months of incubation.

Half life of Thiram in Soil: The half - life of Thiram in soil at $25^{\circ} \mathrm{C}, \mathrm{pH} 7.8$, determined in this study is 10 days. The soil half-life for Thiram was reported as 15 days (Wauchope et al., 1992). Ordelman (1993) reported that Thiram is hydrolyzed with a half life of 4 days at $\mathrm{pH} 5.7,47$ days at $\mathrm{pH} 7$ and 140 days at $\mathrm{pH}$ 8.

\section{REFERENCES}

Abdel-Mallek, A.Y., Abdel-Kader, M.I. A and Shonkeir, A. M. A (1992). Selective effect of the fungicide copperoxychloridi on fungal flora, respiration and decay of some organic matters in soil. Sohag Pure and Applied Bulletin. Faculty of Science. Assuit University. 8: 169-180.

Abdel-Mallek, A.Y., Mazen, M.B., ALLam, A.D and Hashem, M (1997). Specific Responses of Some Phytopathogenic Fungi to Fungicides. Czech Mycology. 50(1): 35-44.

Ali, T.M., Abdelbagi, A.O and Elsheikh, E. A. M (2008). Microbial degradation of endosulfan and lindane by endogenous soil microorganisms. The First African Congress in Pesticides and Toxicology Sciencies, 8-11 Nov. 2008.

Ayanaba, A., Verstraete, W and Alexander, M (1973). Formation of Dimethylnitrosamine, a carcinogen and mutagen, in soils treated with nitrogen compounds. Soil Sci. Soc. Am. Proc. 37:565-568.

Ekundayo, E. O (2002). Effect of common pesticides used in the Niger delta basin of southern Nigeria on soil microbial populations. Environ Monit Assess 89: 3541, 2003.
Elsaid, O.E.G and Abdelbagi, A.O (2010). Survey of Naturally Occurring Microorganisms in Different Soils from Sudan. IJAAR. 5, 3:301-308.

Elsaid, O.E.G., Abdelbagi, A.O and Elsheikh, E.A.E (2009). Effect of Fertilizers (Activators) in Enhancing the Microbial Degradation of Endosulfan in Soil. Res. J. Environ. Toxicol. Pp. 1-10.

Hayes, W. J and Laws, E.R. (ed.) (1990). Handbook of Pesticide Toxicology, Vol. 3, Classes of Pesticides. Academic Press, Inc., NY. Pp. 912.

Houseworth, L.D and Tweedy, B.G. (1973). Effect of Atrazine in combination with Captan or Thiram upon Fungal and Bacterial Populations in the Soil. Plant Soil. 38: $493-500$.

Kauffman, A. K (1987). Applied bioremedial technology. Applied Biotreatment Assoc., Washington, DC.

Kawasaki, M (1980). Experiences with the test scheme under the chemical Control Law of Japan: An approach to structure-activity correlations. Ecotoxicol. Environ. Safety, 4: $444-454$.

Klinsari, A.A (1983). Pesticides and Plant Microflora. Zinatne, Riga. Pp. 168. In Russian.

Kruglov, U.V (1991). Soil Microflora and Pesticides. Agroprom, Moscow. Pp. 128. In Russian.

Mohamed, A.T (2009). An investigation of the Role of soil Microorganisms in the Degradation of Oxyfluorfen (Goal) Herbicide. M. Sc. Thesis, U of K.

Müller, K., Magesan, G.N and Bolan, N.S (2006). A critical Review of the Influence of Effluent Irrigation on the Fate of Pesticide in Soil. Agric. Ecosys. Environ. 120: $93-116$.

NIOSH. (1986). National Institute of Safety and Health. Registry of toxic effects of chemical substances (RTECS).

Odeyemi, O and Alexander, M (1977). Use of fungicideresistant rhizobia for legume inoculation. Soil Biol. Biochem. 9: 247-251.

Ordelman, H.G.K (1993). Dithiocarbamaten. Een analyse van de problemathiek in aquatisch milieu. RIZA nota. 93: 025.

Osman, A.G (2006). Degradation of the Fungicide Azoxystration by Soil Microorganisms. U. of K. Agric. Sci. 14: 124-134.

Osman, A.G., Kalinin, V.A., Emtsev, V.T and Bikov, K.V (2005). Effect of New Broad Spectrum Fungicide Amistar on Soil Microorganisms in Field Conditions. J. Sci. Tech. 6: 207-213.

Osman, A.G., Emtsev, V.T., Kalinin, B.A., Smirnov, A. N and Bikov, K.B (1999). Effect of new broad spectrum 
fungicide Amistar on beneficial microorganisms and some strains of phytophthora infestants (In Russian). Journal of Moscow Timiryazev Agricultural Academy. 1: 139-145.

Racke, K. D and Coats, J. L (1990). Enhanced biodegradation of pesticides in the environment. American Chemical Society Symposium Series.Pp. 426.

Rayan, J., Garabet, S., Harmsen, K and Rashid, A (1996). A soil and plant analysis manual adapted for the west Asia and North Africa region. ICARDA, Aleppo, Syria. Pp. 140.

Richardson, L.T (1954). The persistance of Thiram in soil and its relationship to the microbiological balance and damping - off control. Canad. J. Bot. 32: 335-346.

Roberti, R., Badiali, F., Pisi, A., Veronesi1, A., Pancaldi, D and Cesari, A (2006). Sensitivity of Clonostachys rosea and Trichoderma spp. as Potential Biocontrol Agents to Pesticides. Phytopathology 154: 100 - 109.

Shirkot, C.K., Gupta, K.G (1985). Accelerated tetramethylthiuram disulfide (TMTD) degradation in soil by inoculation with TMTD-utilizing bacteria. Bull. Environ. Contam. Toxicol. 35: 354-361.

Shirkot, C.K., Shirkot, P., Dhall, S.P., Gupta, K.G (1990). Effectiveness of Pseudomonas aeruginosa for detoxificaton of tetramethylthiuram disufide (TMTD) from contaminated soil. Bull. Environ. Contam. Toxicol. 44: 317-324.

Suleman, T.F.K (1983). Phytotoxicity of Triazine herbicides, role of organic additions and soil micro flora in their degradation. Ph.D. (Biology) Thesis. Moscow Agricultural Academy, Moscow, Russia. In Russian.

Tepper E.Z., shilinkova, U.K and perverzeva G.E (1993). Manual of microbiology, Mosco, kolas, $4^{\text {th }}$ Edition. Pp. 170.

U.S. EPA (1992 (March 2)). Ethylene bisdithiocarbamates (EBDCs); Notice of intent to cancel and conclusion of Special Review. Federal Register. US GAO, Washington, DC. 57(41):7434-7530.

U.S. National Libarary of Medicine (1995). Hazardous Substances Data Bank. Bethesda, MD.4-5.

Wauchope, R.D., Buttler, T.M., Hornsby A.G., Augustijn Beckers, P. W. M and Burt, J.P (1992). Pesticide properties database for environmental decisionmaking. Rev. Environ. Contam. Toxicol. 123: 1-157, 7-22.

Zinchenko, V.A., Viatkina, N.E and Afanaseva, A.U (1974). Biological methods of determination of toxicity and residuals of pesticides. Manual for practical. Department of Chemical Plant Protection. Moscow Agricultural Academy. 